\title{
Pemetaan Lingkungan Kerja Fisik pada Lantai Produksi IKM “ABC" dengan Software Surfer
}

\author{
Rahmaniyah Dwi Astuti ${ }^{*}$, Bambang Suhardi , Wakhid Ahmad Jauhari ${ }^{3}$ dan Nidya Yutie Pramesti ${ }^{4}$ \\ Program Studi Teknik Industri, Fakultas Teknik, Universitas Sebelas Maret Jl. Ir. Sutami No. 36A, Jebres, Kota \\ Surakarta, Jawa Tengah 57126. \\ Email: niyah22@ gmail.com ${ }^{1}$, bambangsuhardi@staff.uns.ac.id ${ }^{2}$, \\ wakhidjauhari@gmail.com ${ }^{3}$, nidyaprm@yahoo.com ${ }^{4}$,
}

DOI: 10.20961/performa.18.2.33600

\begin{abstract}
Abstrak
Kenyamanan termal sangat berpengaruh terhadap proses produksi, kenyamanan termal itu sendiri salah satunya dipengaruhi oleh kelembaban udara. Penelitian ini bertujuan untuk mengetahui distribusi kelembaban udara pada lantai produksi IKM"ABC" melalui pemetaan dengan software surfer dan untuk mengetahui tingkat kenyaman termal pekerja sesuai dengan Keputusan Menteri Kesehatan Republik Indonesia Nomor 1405/Menkes/SK/XI/2002. Metode yang digunakan dalam penelitian ini adalah pengambilan data kelembaban udara dengan pengamatan langsung sesuai dengan titik yang telah ditentukan dengan berdasarkan SNI 16-7062- 2004 yang nantinya akan diolah melalui software surfer. Dari penelitian ini didapatkan bahwa rata-rata kelembaban udara keseluruhan adalah sebesar $68.1 \%$ dan dari peta kontur didapakan bahwa tidak terdapat zona aman pada lantai produksi IKM"ABC' karena nilai kelembaban udara di semua area melebihi NAB yang telah ditentukan.
\end{abstract}

Kata kunci: Kelembaban Udara, Peta Kontur, Software Surfer

\begin{abstract}
Termal comfort greatly affects a production process, termal comfort itself is affected by humidity. The aims of this research is to determine the distribution of humidity in the production floor of IKM"ABC" and to know the termal comfort level of workers by comparing with Keputusan Menteri Kesehatan Republik Indonesia Nomor 1405/Menkes/SK/XI/2002. The method used in this study is direct observation to collect the air humidity data in accordance with the points that have been determined based on SNI 16-7062-2004 which will be processed through surfer software. From this study it was known that the average of air humidity in the production floor was $68.1 \%$ and from the contour map there was no safe zone on the production floor of IKM"ABC" because the value of air humidity in all areas exceeded the predetermined threshold value.
\end{abstract}

Keywords: Humidity, Contour Map, Software Surfer

\section{Pendahuluan}

Sebuah penelitian yang dilakukan oleh Chukwuma dan Okafor (2014) menyatakan bahwa karyawan merupakan aset penting bagi perusahaan yang berpengaruh dalam keberlangsungan perusahaan. Untuk mencapai hasil yang baik, setiap perusahaan atau organisasi memerlukan karyawan yang mampu, cakap, dan terampil yang bersedia bekerja dengan giat dan berkeinginan untuk mencapai hasil kerja yang optimal. Sinaga (2016) mengungkapkan lingkungan kerja yang baik memiliki peranan penting dalam meningkatkan produktivitas kerja karyawan dalam perusahaan. Karyawan atau pegawai memiliki peranan penting dalam perusahaan. Faktor-faktor lingkungan kerja yang dapat mempengaruhi kenyamanan dan keamanan yaitu iklim kerja, pencahayaan, kebisingan, dan kadar CO (Handayani, 2011). Sementara itu iklim kerja adalah hasil perpaduan antara suhu, kelembaban, kecepatan gerakan udara dan panas radiasi (Permenakertrans, 2011). Dari fakta-fakta tersebut dapat disimpulkan bahwa kelembaban udara sangat berpengaruh terhadap kenyamanan suatu lingkungan kerja.

Lingkungan kerja harus ditangani atau didesain sedemikian rupa sehingga menjadi kondusif terhadap pekerja untuk melaksanakan kegiatan dalam suasana yang aman dan nyaman. Lingkungan kerja yang nyaman sangat dibutuhkan oleh pekerja untuk dapat bekerja secara optimal dan produktif. Sebaliknya, semangat kerja yang rendah dapat berdampak buruk terhadap tujuan-tujuan perusahaan. Karyawan yang memiliki semangat kerja yang rendah memiliki ciri-ciri mudah bosan, tidak bergairah, dan bermalas-malasan dalam melaksanakan pekerjaannya. Kondisi semangat kerja rendah seperti ini dapat menimbulkan masalah di tempat kerja, seperti kecenderungan karyawan untuk menarik diri dari lingkungan kerja, datang terlambat ke tempat kerja, dan pulang lebih awal daripada waktu yang telah ditentukan (Gibson, 2003 dalam Astri Pratiwi, 2012). Kondisi seperti ini tentunya dapat berdampak buruk terhadap performa kerja karyawan dalam mencapai tujuan-tujuan perusahaan. IKM"ABC" merupakan sebuah perusahaan (home industry) yang bergerak dalam bidang pengolahan kue. Hasil studi pendahuluan menunjukan bahwa nilai kelembaban udara 
di IKM "ABC" yaitu 69.5\%, nilai ini berada di luar rentang NAB yang telah ditentukan berdasarkan Keputusan Menteri Kesehatan Republik Indonesia Nomor 1405/Menkes/SK/XI/2002 yaitu suatu lingkungan kerja harus memiliki kelembaban $40 \%$ sampai dengan $60 \%$. Dari masalah tersebut perlu dilakukan perbaikan lingkungan kerja pada lantai Produksi IKM "ABC". Maka dari itu untuk mempermudah perbaikan lingkungan kerja, pada penelitian ini dilakukan pembuatan peta kontur dari kelembaban udara di IKM "ABC" dengan menggunakan software surfer untuk memudahkan dalam pemberian solusi agar tepat sasaran.

\section{Metode Penelitian}

Penelitian ini secara garis besar terdiri dari 4 tahap, yaitu tahap persiapan penelitian, tahap pengumpulan data, tahap pembutan peta kontur dan tahap analisis. Pada tahap persiapan yang dilakukan adalah melakukan studi pendahuluan, identifikasi masalah dan pemilihan metode yang akan digunakan. Metode yang digunakan dalam penelitian ini adalah metode survei lapangan dengan sistem grid. Lalu tahap pengumpulan data yaitu dilakukan adalah pembuatan denah IKM"ABC" dan pengukuran kelembaban di semua area yang terdapat pada lantai produksi IKM"ABC". Pengukuran kelembaban ini menggunakan 4 in 1 Environment Meter Digital yang mempunyai fasilitas humidity meter untuk pengukuran kelembaban udara suatu ruangan tempat kerja. Waktu pengukuran dilakukan selama 3 hari pada jam kerja yaitu mulai dari pukul 08.00 WIB hingga pukul 16.00 WIB dengan interval waktu pengukuran yaitu satu jam, hal ini didasari OSHA. Penetuan titik pengambilan berdasarkan SNI 16-7062-2004. Sedangkan tingkat gradien ketinggian disesusaikan dengan standar pengukuran ASHRAE yaitu $0.1 \mathrm{~m} ; 1.1 \mathrm{~m}$ dan $1.7 \mathrm{~m}$. Berikut adalah tahap pembuatan peta kontur, langkah-langkah pembuatan peta kontur dengan software surfer di lantai produksi IKM"ABC" dapat digambarkan dalam diagram alir.

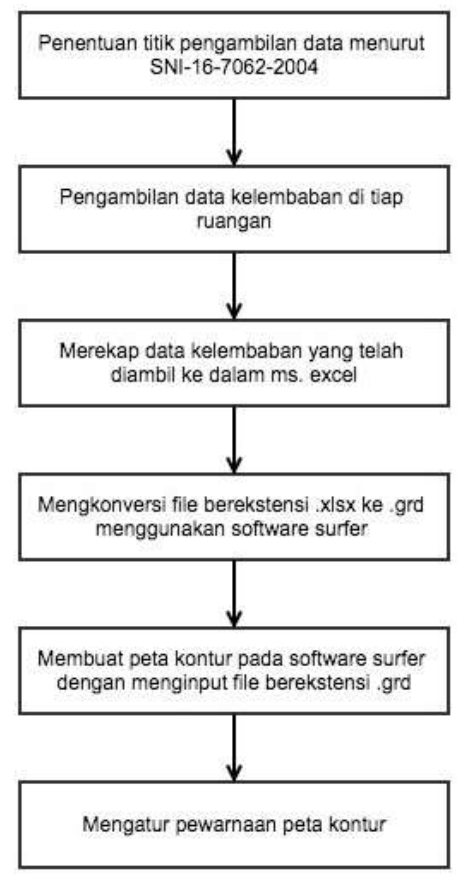

Gambar 1. Diagram Alir Pembuatan Peta Kontur

Tahap terakhir adalah melakukan analisis dari peta kontur kelembaban di lantai produksi IKM "ABC" yang telah dibuat menggunakan software surfer.

\section{Hasil dan Pembahasan}

Hal pertama yang dilakukan adalah pembuatan denah IKM "ABC" yang dapat dilihat pada Gambar 2. Lantai produksi IKM"ABC" ini terdiri dari 6 area yaitu area packing, area gudang bahan 1, area gudang bahan 2, area percampuran, area pembentukan dan area produksi cake dengan ukuran perarea dapat dilihat pada Tabel 1. 


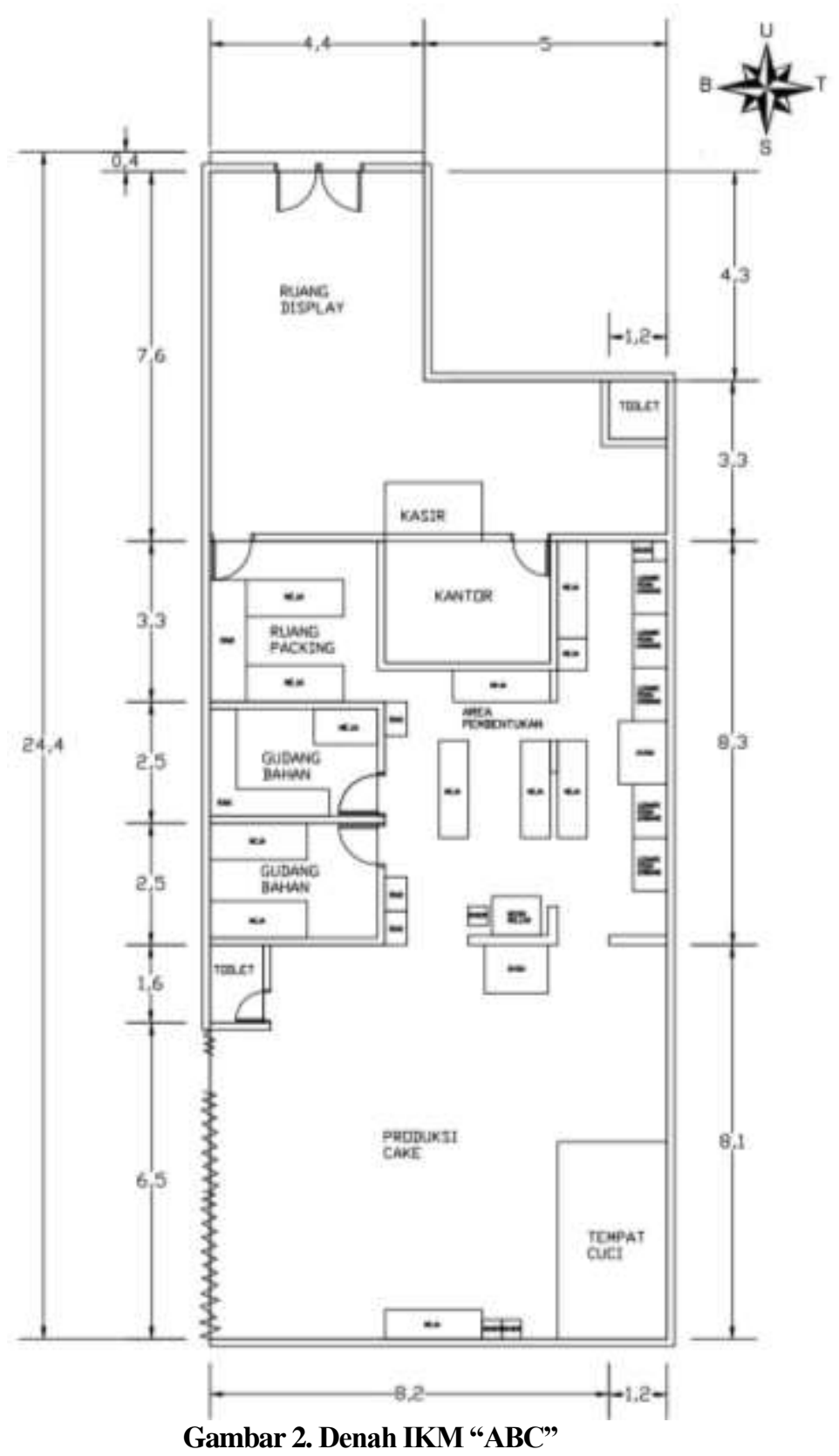

Tabel 1. Luas Area Produksi IKM"ABC"

\begin{tabular}{|c|c|c|c|}
\hline Area Produksi & Panjang $(\mathrm{m})$ & Lebar $(\mathrm{m})$ & Luas $\left(\mathrm{m}^{2}\right)$ \\
\hline Ruang Packing & 3.30 & 2.80 & 9.24 \\
\hline Gudang Bahan Baku 1 & 2.50 & 2.80 & 7.00 \\
\hline Gudang Bahan Baku 2 & 2.50 & 2.80 & 7.00 \\
\hline Area Percampuran & 8.30 & 3.20 & 26.56 \\
\hline Area Pembentukan & 5.80 & 3.40 & 19.72 \\
\hline Ruang Produksi Cake & 8.10 & 9.40 & 76.14 \\
\hline \multicolumn{3}{|c|}{ Total } & 145.66 \\
\hline
\end{tabular}

Setelah mengetahui ukuran dan luas dari tiap area, dilakukan penentuan titik pengambilan data pada tiap area dengan berdasarkan SNI 16-7062-2004 dan mengambil data temperatur di tiap titik yang telah ditentukan selama 3 hari lalu menghitung rata-rata tiap titiknya, setelah itu pembuatan peta kontur kelembaban dengan menggunakan software surfer pada area packing, area gudang bahan 1, area gudang bahan 2 , area percampuran, area pembentukan dan area produksi cake yang akan ditunjukan pada gambar 3 sampai dengan gambar 8. 


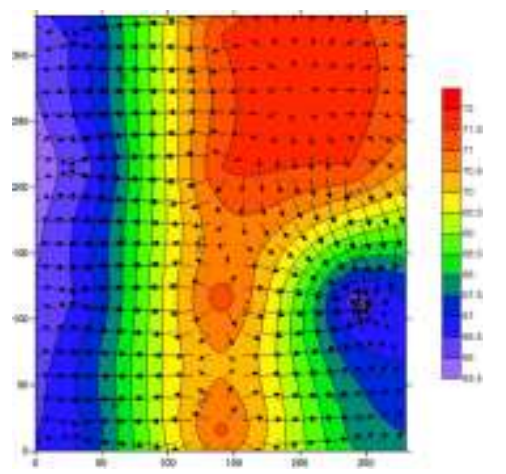

Gambar 3. Peta Kontur Kelembaban Area Packing

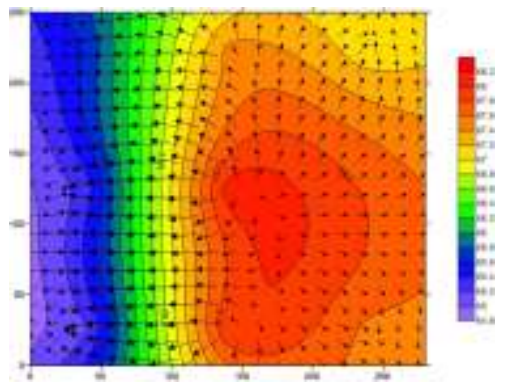

Gambar 5. Peta Kontur Kelembaban Area Gudang 2
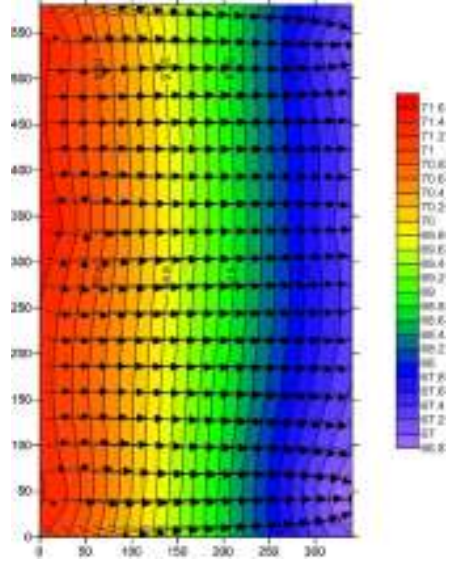

Gambar 7. Peta Kontur Kelembaban Area Pembentukan

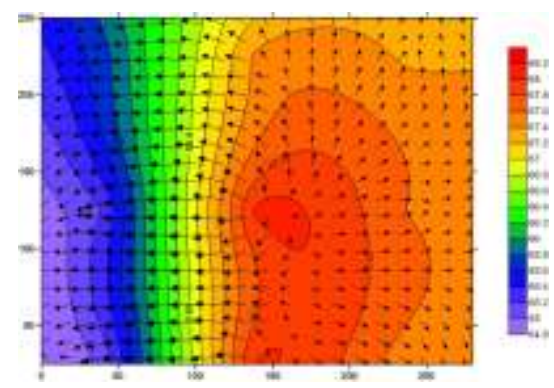

Gambar 4. Peta Kontur Kelembaban Area Gudang 1

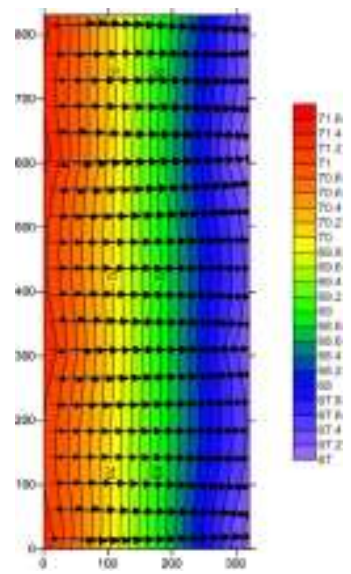

Gambar 6. Peta Kontur Kelembaban Area Percampuran

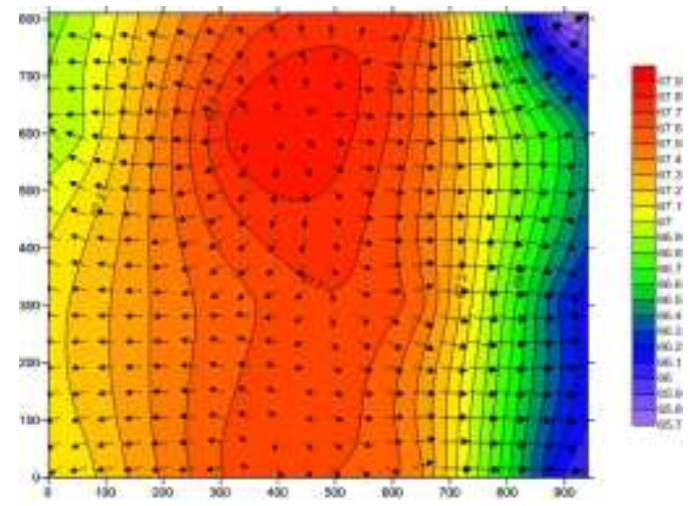

Gambar 8. Peta Kontur Kelembaban Area Produksi Cake

Setelah mengetahui ukuran dan luas dari tiap area, dilakukan penentuan titik pengambilan data pada tiap area dengan berdasarkan SNI 16-7062-2004 dan mengambil data temperatur di tiap titik yang telah ditentukan selama 3 hari lalu menghitung rata-rata tiap titiknya, setelah itu pembuatan peta kontur kelembaban dengan menggunakan software surfer pada area packing, area gudang bahan 1, area gudang bahan 2, area percampuran, area pembentukan dan area produksi cake yang akan ditunjukan pada gambar 3 sampai dengan gambar 8.Dari peta kontur yang telah dibuat dengan menggunakan software surfer dapat terlihat di setiap area yang memiliki nilai kelembaban tertinggi ditunjukan dengan warna merah. Pada area packing sisi yang memiliki nilai kelembaban tertinggi ada di sisi tengah area tersebut, sehingga kelembaban pada area packing menyebar dari sisi tersebut. Lalu kelembaban tertinggi pada area gudang bahan 1 terdapat pada sisi kanan begitu pula pada area gudang bahan 2, pada area percampuran kelembaban tertinggi berada di sisi kiri area tersebut, pada area pembentukan kelembaban tertinggi berada di sisi kanan juga. Dan yang terakhir pada area produksi cake, kelembaban tertinggi berada di sisi tengah area tersebut. Dengan mengetahui sisi dengan nilai kelembaban terekstrem dari tiap area di lantai produksi ini dapat membantu sebuah penelitian dalam menentukan solusi apa yang akan diberikan agar tepat sasaran. 


\section{Simpulan}

Berdasarkan hasil penelitian yang telah dilakukan tahap awal ini adalah kelembaban rata-rata di semua area pada lantai produksi IKM"ABC" berada di atas NAB yang telah ditentukan oleh Keputusan Menteri Kesehatan Republik Indonesia Nomor 1405/Menkes/SK/XI/2002 yaitu sebesar $68.1 \%$ dan dari peta kontur kelembaban diketahui bahwa tidak terdapat zona aman di lantai produksi IKM"ABC" karena nilai kelembaban dari semua area di lantai produksi masih berada di atas $60 \%$, nilai tersebut masih berada di atas NAB yang telah ditentukan. Penelitian selanjutnya masih perlu dilakukan untuk menganalisis kondisi lingkungan fisik dari faktor lain yaitu suhu dan pencahayaan sehingga dapat dilakukan usulan perbaikan kondisi lingkungan secara menyeluruh.

\section{Daftar Pustaka}

Ashrae 55. (2004). Thermal environmental conditions for human Occupancy, American Society of Heating, Refrigerating, and Air-conditioning Engineers. Inc., Atlanta.

Chukmuwa, E. M., \& Ofakor, O. (2014). Effect of Motivation on Employee Productivity: A Study of Manufacturing Companies in Nnewi. International Journal of Managerial Studies and Research (IJMSR) Volume 2, Issue 7, August 2014, PP 137-147 ISSN 2349-0330 (Print) \& ISSN 2349-0.

Handayani, Yuli Sri. (2011). Pengaruh Lingkungan Kerja Terhadap Kinerja Karyawan. Universitas Brawijaya.

Keputusan Menteri Kesehatan Republik Indonesia Nomor 1405/menkes/sk/xi/2002 Tentang Persyaratan Kesehatan Lingkungan Kerja Perkantoran dan Industri.

Menteri Tenaga Kerja dan Transmigrasi. (2011). Peraturan Menteri Tenaga Kerja dan Transmigrasi No PER.13-MEN-X-2011 Tentang Nilai Ambang Batas Faktor Fisika dan Faktor Kimia di Tempat Kerja. Jakarta.

Occupational Safety and Health Administration. (2010). OSHA Technical Manual-Section III: Chapter IV: Heat Stress. Available at: http://www.osha.gov/dts/osta/otm/otm_iii/otm_iii_4.htm.

Pratiwi, Astri. (2012). Pengaruh Suhu Udara Ruangan Kerja Terhadap Semangat Kerja Karyawan PT. Bank Sumut Pusat Medan. Tugas Akhir Universitas Sumatra Utara.

Sinaga, S. (2016). Pengaruh Lingkungan Kerja Terhadap Produktivitas Kerja Karyawan (Bagian Produksi Minyak Kelapa Sawit Pt.Mitra Unggul Pusaka Segati Pelalawan Riau). JOM FISIP Vol. 3 No. 2 Oktober 2016.

Standar Nasional Indonesia. (2004). SNI 16-7062-2004 tentang Pengukuran intensitas penerangan di tempat kerja. Jakarta. 
